\title{
With all this Pseudoscience, Why so Little Pseudotechnology?
}

\author{
Sven Ove Hansson ${ }^{1}$
}

Received: 20 May 2020 / Accepted: 4 June 2020/Published online: 26 June 2020

(C) The Author(s) 2020

\begin{abstract}
After a review of previous uses of the term "pseudotechnology", a definition is proposed: "A pseudotechnology is an alleged technology that is irreparably dysfunctional for its intended purpose since it is based on construction principles that cannot be made to work". The relationship between pseudotechnology and pseudoscience is discussed, and so is the relationship between pseudotechnology and the much weaker concept of technological malfunction. An explanation is offered of why pseudotechnology is much more seldom referred to than pseudoscience: dysfunctional technology usually reveals itself when put to use, whereas dysfunctional science tends to be more difficult to disclose.
\end{abstract}

Keywords Pseudotechnology $\cdot$ Technology $\cdot$ Malfunction $\cdot$ Pseudoscience $\cdot$ Science fiction · Magic

\section{Introduction}

The influence of pseudoscience in today's world is obvious and in important respects ominous. Creationism blocks basic understanding of biology, antivaccinationism and quackery threaten public health, and climate science denialism endangers the future of humankind. With so much pseudoscience, one might expect a similar abundance of pseudotechnology. Gustavo Romero (2018, p. 67) rightly remarked that "as most human products, science and technology can be faked", and that one can therefore expect to find "activities and artifacts presented or offered as scientific or technological which actually are not". But in practice, there is a striking difference in the frequencies with which the concepts of pseudoscience and pseudotechnology are referred to. This was pointed out more than twenty years ago by James McOmber (1999, p. 140), who noted that "[s]cientists may accuse

Sven Ove Hansson

soh@kth.se

1 Royal Institute of Technology (KTH), Stockholm, Sweden 
creationists, parapsychologists, and others of pseudoscience", whereas "few accusations of "pseudotechnology' ever appear." This was confirmed by a Google search in April 2020, which yielded almost 700 times more occurrences of the word "pseudoscience" than the word "pseudotechnology" $(7,910,000$ respectively $11,600)$.

Is this because pseudotechnology does not in fact exist? Perhaps there is nothing, or very little, that stands in the same relation to technology as pseudoscience to science? This is what the late historian and philosopher of technology Ann Johnson indicated in one of her papers:

"Scholars in the technology as knowledge tradition have carefully avoided limiting definitions of technological knowledge in an explicit effort to avoid some of the restrictions that have arisen through the epistemology of science. We may speak of pseudo-science, but never of pseudo-technology. " (Johnson 2005, p. 555)

This article attempts to answer two questions: First, is pseudotechnology an oxymoron, or is it a phenomenon that can and does exist? Secondly, if it can exist, why is it so seldom referred to, in particular in comparison to pseudoscience?

In order to answer these questions, we first need to clarify the meaning of the term "pseudotechnology". In Sect. 2, previous scholarly usage of the term is summarized. Section 3 is devoted to the definition of technology, and Sect. 4 to the relationship between science and pseudoscience. Based on these preparations, a definition of pseudotechnology is proposed in Sect. 5, which also answers our first question. The second question in answered in Sect. 6, and our conclusions are summarized in Sect. 7.

\section{Previous Usage of the Term}

The first documented usage of the term "pseudotechnology" appears to be in a book on science fiction from 1960 by the English novelist and critic Kingsley Amis (1922-1995):

"Science fiction is that class of prose narrative treating of a situation that could not arise in the world we know, but which is hypothesised on the basis of some innovation in science or technology, or pseudo-science or pseudotechnology, whether human or extra-terrestrial in origin." (Amis 1960, p. 18)

Amis's definition has been much quoted in the literature on science fiction, usually without any attempt to further clarify the meanings of its key terms. This usage has sometimes also spread to other areas; for instance Susan Schneider (2016, p. 21) refers to Derek Parfit's philosophical investigations of personal identity as employing "the classic science fiction pseudotechnology of the teleporter and the example of split brains from actual neuroscience cases". Several authors have described pseudotechnology as including, or perhaps being synonymous with, concepts such as magic, superstition, and ritual action (e.g.: Jennnings 1987, pp. 39-40; DasGupta 2006, pp. 447-448; Cottingham 2009, p. 206). In contrast, 
Richard Dale Mullen (1915-1998) made an interesting distinction between three versions of technology that appear in science fiction: natural technology (usually called just technology), supernatural technology (also called magical technology), and pseudonatural technology (also called pseudotechnology). Supernatural technology was based on the assumptions "that mind and spirit may exist independent of body and that minds can act on distant bodies". In contrast, pseudotechnology was congruous with the assumptions that "mind is necessarily dependent on body and that an individual mind can act only on the body in which it exists". As examples of pseudotechnology he mentioned Icarus's wings and Isaac Asimov's thiotimoline, which is a fictitious chemical substance with highly unusual properties (RDM 1978, p. 292).

Mario Bunge (1919-2020) was the only major philosopher who has repeatedly and extensively discussed pseudotechnology and its relations to technology. His discussions on pseudotechnology have to be understood against the background of his somewhat unconventional definition of technology. In an article published in 1966 he took "technology" and "applied science" to be synonyms (Bunge 1966, p. 329). In 1976 he defined technology as a body of knowledge that satisfies the following two criteria:

"(i) it is compatible with science and controllable by the scientific method, and

(ii) it can be employed to control, transform or create things or processes, natural or social, to some practical end deemed to be valuable." (Bunge 1976, p. 154)

This definition has two notable consequences. First, in line with Bunge's previous work, technology is still considered to be applied science. Secondly, he treats technology as covering a much larger range of human activities than what is common. His notion of technology is rather similar to the older notion of practical arts (see Sect. 3). As examples of pseudotechnologies he included astrology, alchemy, homeopathy, chiropractic, Lysenkoism, psychoanalysis, and graphology, most of which would more commonly be described as distortions of other activities rather than of technology (Bunge 1976, p. 157).

In later publications, Bunge has recognized that technology is not entirely based on science, but also on "the work of highly skilled and imaginative artisans", whose ideas are not based on science (Bunge 1985, p. 220. Cf. Bunge 1988). This is in line with modern research in the history and philosophy of technology, which has increasingly emphasized the independence of technology and its extensive use of knowledge not derived from science (Radder 2009; Hansson 2013b). However, this modification of his previous standpoint did not have much impact on his view of pseudotechnology. His most well-developed definition of pseudotechnology is part of a joint definition for "pseudoscience or pseudotechnology". Both of them are said to have "a community of believers who call themselves scientists or technologists although they do not conduct any scientific or technological research". Furthermore, both are said to have a fund of (alleged) knowledge that "contains numerous untestable or even false hypotheses in conflict with well confirmed scientific hypotheses". He does not directly address the distinction between 
pseudoscience and pseudotechnology, but indicates that those so-called pseudosciences that are devoted to "practical problems concerning human existence" rather than "cognitive problems" are pseudotechnologies, rather than pseudosciences (Bunge 1983, pp. 223-224).

Thus, Bunge identifies pseudotechnology as technology-like phenomena that fail to be based on science. Several other authors have taken a similar approach. Barry Beyerstein (1996, p. 4) defines technology essentially as applied science, and like Bunge he considers the so-called pseudosciences that are devoted to practical achievements as "really pseudotechnologies". Martin Mahner follows Bunge in defining technology as a practical design process performed "with the help of knowledge gained in basic or applied science", and he consequently defines a pseudotechnology as "a technological field based on some pseudoscience". He introduces a special term, "paratechnic", to denote "a crackpot technic without any elaborate pseudoscientific background, or at most with a traditional magical background theory" (Mahner 2007, pp. 539 and 548). Schoijet (2009, p. 434) classifies eugenics as a pseudotechnology, largely because of its lack of a scientific basis, and and Tuomela (1987, p. 95) maintains that if a pseudoscience is concerned with practical problems about "how to bring about a certain effect", then it contains aspects of pseudotechnology.

In a discussion on different forms of medical technology, Lewis Thomas used the term "pseudotechnology", or synonymously "magical technology", for traditional technologies with no base in science, lamenting that we have got used to pseudotechnologies when they have "gone through our cyclical fads and fashions, generation after generation, ranging from bleeding, cupping, and purging, through incantations and the reading of omens, to prefrontal lobotomy and metrazol convulsions" (Thomas 1974, p. 100). This usage has not received much following in the discussion on medical technologies.

Ingemar Nordin (2000, p. 303) used the term in a somewhat different way. After pointing to "the condition that therapies must work in order to be useful and that functionality may be determined by scientific means", he wrote: "Functionality is also the criterion of demarcation between quackery and real medicine, between pseudotechnology and real technology." Here, the main focus is on functionality rather than on a scientific base. Lack of functionality may, but need not, be determined with the means of science. A similar usage of the term can be found in an article by Stanley Changnon (1973, p. 642) on a quite different topic, namely weather modification technology. He deplored that "the majority of the public, and many decision makers, believe that weather modification is a pseudo-technology". Although he is not entirely clear, he seems to mean by this that the functionality of the technology was questioned by the general public and by decision makers.

In summary, we have identified two major usages of the (comparatively rare) term "pseudotechnology". One of them originates in the literature on science fiction, but it can also be found in a few texts referring to philosophical examples, medical technologies, and weather modification. Its main criterion for distinguishing between technology and pseudotechnology is the severe and irreparable nonfunctionality of the latter. In order for an object or a process to be a pseudotechnology, it is not sufficient that it does not work, like a hammer with a 
loose handle or an elevator with a motor too weak to hoist the cab. The criterion is instead that its very construction principles cannot work, like Superman's X-ray vision or Dr. Whos's time machine.

The other major usage originates in Mario Bunge's writings, and can mostly be found in texts directly influenced by his work. It is based on a conception of technology as highly dependent on science, and it defines pseudotechnology as a (putative) technology that lacks a scientific basis. Writers in this tradition seem to implicitly assume that this lack of a scientific basis makes the pseudotechnology non-functional. We can therefore interpret this usage as referring to a subset of the cases covered by the first usage, namely to (putative) technologies that exhibit a severe and irreparable non-functionality due to lack of a scientific basis.

\section{What is Technology?}

In order to clarify the meaning of "pseudotechnology", we need to have a clear picture of what we mean by technology. This is a fairly new concept. It has largely replaced the previously more popular concept of "practical arts", which had a much wider scope and included not only the crafts but also agriculture, hunting, medicine, warfare, and much of what we today call the fine arts. (Hansson 2015 pp. 13-15).

The word "technology" is of ancient Greek origin, but it was not much used until the nineteenth century, when it was increasingly employed to denote knowledge about the practical arts, in particular those that were executed by craftspeople. Increasingly, it referred primarily to knowledge about how to construct and use tools and machines, especially in factories and large workshops. The 1909 Webster's Second New International Dictionary defined technology as "the science or systematic knowledge of industrial arts, especially of the more important manufactures, as spinning, weaving, metallurgy, etc." (Tulley 2008, p. 94). In the English language the word "technology" also acquired another meaning: It referred to the tools, machines, and procedures used in industry, rather than to knowledge about these tools, machines, and procedures. This usage arose around the year 1900 (Sebestik 1983; Mertens 2002; Tulley 2008; Hansson 2015, pp. 16-17). Today this is the dominant usage, and it is also the sense in which we use the term here.

\section{The Science-Pseudoscience Relationship}

In both the major usages referred to in Sect. 2, the term "pseudotechnology" is conceived in analogy with "pseudoscience". We therefore need to study the relationship between science and pseudoscience as a prolegomenon to defining "pseudotechnology".

As a first rough approximation, a pseudoscience can be defined as a doctrine that is claimed to be scientific in spite of not being so. Since the concept of pseudoscience is based on that of science, we cannot make the meaning of "pseudoscience" more precise without having a reasonably clear concept of science. The two major problems in defining science concern its the scope and the quality required of its constituents. 
The scope of science, or in other words the areas of knowledge included in that description, is the result of historical contingencies. The English word "science" originally referred broadly to various kinds of both practical and theoretical knowledge. It acquired a new, much more restricted meaning in the eighteenth century when it was adopted by researchers performing empirical studies of natural phenomena. They used this term at least in part to distance themselves from the less empirically minded "natural philosophers" at the universities (Layton 1976, p. 689). Today, "science" refers to the natural sciences and other fields of research that are considered to be similar to them. In contrast, the German word "Wissenschaft" and its cognates in other Germanic languages have a wider scope, and cover all the academic disciplines, including the humanities. The larger scope of Wissenschaft has the advantage of accentuating that all these knowledge disciplines form a community with common values and principles, and with mutual respect for each other's methods and results. This is particularly important in discussions of the science-pseudoscience demarcation, since the divergence between legitimate history and pseudohistorical teachings such as Holocaust denial largely coincides with that between science and pseudoscience (Hansson 2007, pp. 260-261; 2009 pp. 238-239). It is therefore a sensible choice to focus on the wider concept of Wissenschaft ("science in a broad sense"). However, for our present purposes we can leave the choice between the traditional and the broadened view of science as an open issue.

Let us now turn to the quality criterion of science. What legitimizes science is that it provides, at each point in time, the most epistemically warranted information in its areas of knowledge available at that time. Many attempts have been made to specify philosophical rules for determining whether or not a statement or practice satisfies this criterion. I have argued elsewhere that due to the unceasing development of science, which involves fundamental changes in methodologies and modes of inference, no time-less specification of the criterion of epistemic warrant is possible (Hansson 2009, p. 239). (This has the important implication that the determination whether a particular claim or doctrine is scientific is a task for experts in the respective area. It is not an issue to be solved by philosophers examining the statements per se.) For our present purposes we can leave it open whether or not the criterion of "currently most epistemically warranted information" can be further specified with timeless methodological criteria.

Importantly, not all knowledge claims that fail to satisfy the quality criteria of science can be classified as pseudoscience. For instance, we need to distinguish between pseudoscience and various forms of bad science and fraud in science. The major characteristic of pseudoscience that distinguishes it from these other aberrations from science is the presence of a deviant doctrine. Bad science usually results from failed attempts to do good science and to adhere to the evidential criteria applied in bona fide science. It has no ideology of its own. In contrast, all the pseudosciences - homeopathy, creationism, Lysenkoism etc.-are characterized by staunch commitment to doctrines that are irreconcilable with legitimate science.

In summary, the three defining criteria of pseudoscience are that it refers to issues within the domains of science (the criterion of scientific domain), that it has severe shortcomings in terms of reliability or epistemic warrant (the criterion of 
unreliability) and that it involves a doctrine falsely claimed to represent the most reliable knowledge on its subject matter (the criterion of deviant doctrine) (Hansson 2013a).

\section{Defining Pseudotechnology}

As we saw in Sect. 2, most usages of the term "pseudotechnology" refer to devices or processes that lack the functionality ascribed to them. This is unsurprising, since our expectations on a technology or technological device can usually be expressed in terms of a function, or a way in which we can use it (Kroes 2012). It would be strange to classify a device or process as a pseudotechnology if we can use it successfully for its intended purpose. Consequently, non-functionality is a necessary criterion for pseudotechnology. Notably, this implies that a putative technology can only be a pseudo technology in relation to a particular function or intended usage. If we do not know the intended use of an artefact, then we cannot determine if it fulfils its intended use, and therefore we cannot know whether or not it is a pseudotechnology.

Extensive historical evidence and thorough philosophical analysis have given rise to a broad consensus among technology scholars that technology is not, and has never been, based exclusively on science. Advanced technology has existed since long before modern science. Even today, the construction and use of technologies is largely based on more or less systematized practical experiences, such as rules of thumb and tacit knowledge, rather than (or in addition to) science (Houkes 2009; Hansson 2013b; Norström 2013). Against this background, it would be inadequate to require, as some authors have done, that putative technologies have to be based on science in order to avoid being classified as pseudotechnologies.

Comparisons between pseudotechnology and pseudoscience can be facilitated by the observation that the distinction between science and pseudoscience can also be expressed in terms of functionality. We can identify the function of science as that of providing us with explanations, understanding, and systematic knowledge about the world. For instance, one of the major differences between creationism and evolution theory is that the latter is an indispensable tool for explaining and systematizing biological knowledge, whereas creationism serves no such purpose. In general, we can describe pseudoscience as dysfunctional (putative) science, and pseudotechnology as dysfunctional (putative) technology.

However, there is an important difference that makes it necessary to qualify the analogy. We noted in Sect. 4 that science represents the currently best available (most epistemically warranted) information about its subject matter. This means that in order to determine whether a statement or a doctrine is scientific, we compare it to the maximally functional information in its area. This is not how we conceive technological functionality. For your computer to be functional, it is certainly not necessary that it functions as well as the best computers available.

Since "pseudo" means false, that which we call "pseudo-X" should indeed not be $\mathrm{X}$. This is true of pseudoscience; that astrology is a pseudoscience implies that it is not a science. Applying this criterion to (pseudo)technology will further highlight 
how low the threshold of functionality is that distinguishes between technology and pseudotechnology. Suppose that your bicycle has two flat tyres and the chain is broken. It is then completely dysfunctional; you cannot ride it. However, it is still a bicycle, and it is certainly also still a technological artefact. Calling it pseudotechnology would be equally inadequate as calling it a pseudo-bicycle. An immediate reason why it is a bicycle is of course that it can presumably be repaired, and will then be functional again. But suppose that you take it to the repair shop. The technician tells you that both the top tube and the down tube have big cracks that cannot be repaired. This means that you will have to downgrade the bike from "in need of repair" to "beyond repair", but it is still a bicycle, and neither a pseudobicycle nor pseudotechnology.

If even a permanently useless device is not pseudotechnological, how can the criterion of lacking functionality be employed to demarcate pseudotechnology? Can there be a lower degree of functionality than that of not functioning at all? Yes, there can, if we also consider potential functionality, or functionality in principle. Although the bicycle in this example cannot be made to work, it is based on wellfunctioning principles, and other devices based on these same principles can be made to work. In this it differs for instance from a perpetuum mobile, which is based on principles that cannot be made to work. In summary, pseudotechnology can be characterized as follows:

A pseudotechnology is an alleged technology that is irreparably dysfunctional for its intended purpose since it is based on construction principles that cannot be made to work.

The construction principles mentioned in this definition have a role similar to that of the deviant doctrine mentioned in the definition of pseudoscience in Sect. 4. However, as already mentioned, although the construction principles may refer to science, they need not do so.

The application of this definition will be ambiguous if it is unclear what the construction principles are. One potential example of this is dowsing. The movements of a dowsing device (rod or pendulum) depend on the dowser's own expectations, conveyed through small subconscious muscular movements. If a dowser searching for water recognizes plants that only grow in soil with high humidity, then this can induce muscular movements that move the dowsing-rod when he is close to these plants. However, if the dowser's chances to achieve betterthan-random expectations are eliminated with methods such as proper blind-folding, then the results will not be better than random (Zusne and Jones 1982). Dowsing is usually presented as being based on some sort of (non-existent) "energy field", which is claimed to be detectable by humans with a dowsing-rod, but not with physical instruments. This description of a dowsing-rod is a clear case of a pseudotechnology. However, if the dowsing-rod were instead presented as a method to elicit the dowser's intuitive beliefs about suitable sites for well-drilling, then it could not so easily be dismissed as a pseudotechnology. In practice, it is implausible that anyone would promote dowsing with reference to its actual mode of action as an indicator of the dowser's expectations. Therefore, for practical purposes, dowsing is a clear example of a pseudotechnology. 


\section{The Viability of Pseudotechnology}

In the previous section we answered one of our questions from the introduction, namely whether pseudotechnology is a misconstrued conception or a well-definable phenomenon that can and does exist. We found that it can in fact be plausibly defined, and that there are clear examples of devices that satisfy the description. We will now turn to the second question, namely: Why do we hear much more seldom about pseudotechnology than about pseudoscience? In order to answer that question, we will have use for the following concept:

A claim is immediately falsifiable if a single, easily made, observation is sufficient to conclude that it is false.

For instance, if I tell you when you are at home that there is a white horse standing at your front door, then you can easily check my claim by opening the front door and looking out. If the claim is wrong, then it is an easily exposed falsehood. Many, perhaps most, of the technological devices we use-at home and at work-come with claims of a very high degree of functionality. They are supposed to work every time we put them to use. This makes their claimed functionality immediately falsifiable. For instance, a desk lamp should light every time you turn it on. If it does not light, then you know that the salesperson was wrong when she claimed that it would work. That claim was immediately falsifiable. This is the reason why few attempts are made to sell lamps that do not light, clocks with immovable hands, or ovens that do not heat.

In contrast, scientific claims tend to be much more difficult to evaluate. For instance, it is easy to determine if a light bulb based on new physical principles actually emits light, but it can be much more difficult to assess an offered physical explanation of how it works.

There are a few cases in which pseudotechnologies have been peddled with some success although their claimed functionality is immediately falsifiable. The most clear examples are perpetual motion machines and cold fusion (Park 2008). These are of course machines that should produce energy reliably if they worked. There are essentially two ways to fool people into investing in them. One is to claim that the machine is under development. The other is to equip it with hidden contrivances giving the incorrect impression that it is actually producing energy. Similar methods have been employed in so-called gold-from-seawater schemes (which are in fact gold-from-duped-investors schemes) (Naylor 2007). However, these scams seem to be relatively marginal phenomena, due largely to the immediate falsifiability of the claims in question.

Instead, most cases of successfully promoted pseudotechnologies are claimed to have effects that are not immediately falsifiable. The alleged effects of these devices are so ill-defined and/or irregular that it is difficult to determine if the effects are real. This applies to various devices claimed to have positive effects on human health, such as appliances for magnetic healing (Macklis 1993), Wilhelm Reich's orgone accumulator (Gardner 1957, pp. 250-262; Lugg 1987, pp. 227-228), and energy-balancing bracelets (Barrett 2008). Other examples are the e-meter used by 
scientologists (Bigliardi 2016), cameras for aura photography (Nickell 2000), and various gadgets used to detect ghosts (Nagar and Choudhary 2016).

A particularly interesting case is cryonics, the low-temperature freezing of human corpses with the stated purpose of future resurrection. The chances that the persons who are now being frozen will return to life are practically indistinguishable from nil (Monette 2012; Shoffstall 2016; Shermer 2018). However, since the promised resuscitation attempts are supposed to take place far into the future, the outcome of the cryonic process is very far from immediate falsifiability, which may be an important part of the explanation why this business has customers.

\section{Conclusion}

We set out to answer two questions. The first was whether pseudotechnology is a well-definable concept denoting something that exists. After some preparative work we answered that question in Sect. 5. The conclusion was that pseudotechnology can reasonably be defined as a putative technology that is irreparably dysfunctional since it is based on construction principles that cannot be made to work. There are indeed examples of pseudotechnology in that sense.

Our second question was why there is much less discussion about pseudotechnology than about pseudoscience. In Sect. 6 we found an explanation: Many, probably most, technological devices are required to have an immediate effect, which will ensue every time we employ them. If such a device does not work, then that is easily discovered. This leaves no scope for permanently dysfunctional pseudotechnologies.

However, there are exceptions to this. Some technologies have effects that cannot be so easily tested. This is usually because the intended effect is ill-defined or irregular. Such pseudotechnologies can survive simply because their dysfunctionality cannot easily be ascertained. These are also the devices that vigilance against pseudotechnology should put focus on. Dysfunctional devices claimed to have welldefined and regular effects will reveal themselves as soon as they are put to use.

Acknowledgements Open access funding provided by Royal Institute of Technology.

Open Access This article is licensed under a Creative Commons Attribution 4.0 International License, which permits use, sharing, adaptation, distribution and reproduction in any medium or format, as long as you give appropriate credit to the original author(s) and the source, provide a link to the Creative Commons licence, and indicate if changes were made. The images or other third party material in this article are included in the article's Creative Commons licence, unless indicated otherwise in a credit line to the material. If material is not included in the article's Creative Commons licence and your intended use is not permitted by statutory regulation or exceeds the permitted use, you will need to obtain permission directly from the copyright holder. To view a copy of this licence, visit http:// creativecommons.org/licenses/by/4.0/. 


\section{References}

Amis K (1960) New maps of hell. A survey of science fiction. Harcourt, Brace, New York

Barrett S (2008) Q-Ray bracelet marketed with preposterous claims. Downloaded 1 May 2020 from https://quackwatch.org/related/PhonyAds/qray/

Beyerstein BL (1996) Distinguishing science from pseudoscience. Department of Psychology, Simon Fraser University. Prepared for The Centre for Curriculum and Professional Development, Victoria, B.C., Canada. Downloaded 30 April 2020 from https://www.dcscience.net/beyerstein_science_vs_ pseudoscience.pdf

Bigliardi S (2016) Nuclear waste, conspiracies, and E-meters: remarkable religion and technology. Zygon 51(3):661-683

Bunge M (1966) Technology as applied science. Technol Cult 7:329-347

Bunge M (1976) The philosophical richness of technology. In: PSA: Proceedings of the biennial meeting of the philosophy of science association, vol 1976. Philosophy of Science Association, pp. 153-172

Bunge M (1983) Treatise on Basic Philosophy, Volume 6, Epistemology \& Methodology II: Understanding the World. Reidel, Dordrecht

Bunge M (1985) Treatise on basic philosophy, volume 7, Epistemology and Methodology: Philosophy of Science and Technology. Reidel, Dordrecht

Bunge M (1988) The nature of applied science and technology. In: Cauchy B (ed), Philosophy and Culture: Proceedings of the XVIIth Congress of Philosophy, vol 2. Éd. Montmorency, Montréal, pp 599-604

Changnon SA (1973) Weather modification in 1972: up or down? Bull Am Meteor Soc 54(7):642-646

Cottingham J (2009) The lessons of life: Wittgenstein, religion and analytic philosophy. In: Glock H-J, Hyman J (eds) Wittgenstein and Analytic Philosophy: Essays for PMS Hacker. Oxford University Press, Oxford, pp 203-227

DasGupta S (2006) Being John Doe Malkovich: Truth, imagination, and story in medicine. Lit Med 25(2):439-462

Gardner M (1957) Fads and fallacies in the name of science. Dover, New York

Hansson SO (2007) Values in pure and applied science. Found Sci 12:257-268

Hansson SO (2009) Cutting the Gordian Knot of Demarcation. Int Stud Philos Sci 23:237-243

Hansson SO (2013a) Defining pseudoscience-and science. In: Massimo P, Maarten B (eds) The philosophy of pseudoscience. Chicago University Press, Chicago, pp 61-77

Hansson SO (2013b) What is technological knowledge? In: Inga-Britt S, de Vries MJ (eds) Technology teachers as researchers, Sense Publishers, Rotterdam, pp 17-31

Hansson SO (2015) Science and technology: what they are and why their relation matters. In: Hansson SO (ed) The role of technology in science. Philosophical perspectives. Springer, Dordrecht, pp 11-23

Houkes W (2009) The nature of technological knowledge. In: Meijers A (ed) Handbook of the Philosophy of Science, Volume 9: Philosophy of Technology and Engineering Sciences. Elsevier, Hoboken, pp 309-350

Jennings TW (1987) Ritual studies and liturgical theology: an invitation to dialogue. J Ritual Stud 1(1):35-56

Johnson A (2005) Revisiting technology as knowledge. Perspect Sci 13(4):554-573

Kroes P (2012) Technical artefacts: creations of mind and matter a philosophy of engineering design. In: Pieter V (ed) Philosophy of engineering and technology. Springer, Berlin

Layton ET (1976) American ideologies of science and engineering. Technol Cult 17:688-701

Lugg A (1987) Bunkum, flim-flam and quackery: pseudoscience as a philosophical problem. Dialectica 41(3):221-230

Macklis RM (1993) Magnetic healing, quackery, and the debate about the health effects of electromagnetic fields. Ann Intern Med 118:376-383

Mahner M (2007) Demarcating science from non-science. In: Kuipers T (ed) Handbook of the philosophy of science: general philosophy of science - focal issues. Elsevier, Amsterdam, pp 515-575

McOmber JB (1999) Technological autonomy and three definitions of technology. J Commun 49(3): 137-153

Mertens J (2002) Technology as the science of the industrial arts: Louis-Sébastien Lenormand (1757-1837) and the popularization of technology. History Technol 18:203-231

Monette M (2012) The church of cryopreservation. CMAJ 184(7):749-750 
Nagar S, Choudhary S (2016) Is there a ghost out there...? Science Reporter, pp 25-29

Naylor RT (2007) The alchemy of fraud: Investment scams in the precious-metals mining business. Crime Law Soc Change 47:89-120

Nickell J (2000) Aura photography: a candid shot. Skeptical Inquirer 24(3):15-17

Nordin I (2000) Expert and non-expert knowledge in medical practice. Med Health Care Philos 3(3):295-302

Norström P (2013) Engineers' non-scientific models in technology education. Int J Technol Des Educ 23:377-390

Park RL (2008) Fraud in science. Soc Res Int Q 74(4):1135-1150

Radder H (2009) Science, technology and the science-technology relationship. In: Meijers A (ed) Handbook of the philosophy of science philosophy of technology and engineering sciences, vol 9. Elsevier, Amsterdam, pp 65-91

RDM (1978) Supernatural, pseudonatural, and sociocultural fantasy. Sci Fiction Stud 5(3):291-298

Romero GE (2018) Scientific Philosophy. Springer, Berlin

Schneider S (2016) Science fiction and philosophy: from time travel to superintelligence. Wiley, Hoboken Schoijet M (2009) On pseudoscience. Critique 37(3):425-439

Sebestik J (1983) The rise of the technological science. History and Technology 1:25-43

Shermer M (2018) Heavens on Earth The Scientific Search For The Afterlife, Immortality, and Utopia. Henry Holt and Co, New York

Shoffstall GW (2016) Failed futures, broken promises, and the prospect of cybernetic immortality: toward an abundant sociological history of cryonic suspension, 1962-1979. PhD thesis. University of Illinois at Urbana-Champaign.

Thomas L (1974) The future impact of science and technology in medicine. Bioscience 24(2):99-105

Tulley RJ (2008) Is there techne in my logos? On the origins and evolution of the ideographic termtechnology. Int J Technol Knowl Soc 4:93-104

Tuomela R (1987) Science, protoscience, and pseudoscience. In: Pitt JC, Pera M (eds) Rational Changes in Science. Reidel, Dordrecht, pp 83-101

Zusne L, Jones WH (1982) Anomalistic psychology. Lawrence Erlbaum, Hillsdale

Publisher's Note Springer Nature remains neutral with regard to jurisdictional claims in published maps and institutional affiliations. 